\title{
Numerical analysis of heat exchange process in the biomass carbonisation reactor
}

\author{
Robert Zarzycki ${ }^{1, *}$, and Justyna Jędras ${ }^{1}$ \\ ${ }^{1}$ Czestochowa University of Technology, Department of Energy Engineering, Brzeźnicka 60a, 42-201 Częstochowa, Poland
}

\begin{abstract}
The study presents the problem of heat exchange in the biomass carbonisation reactor with cyclic operation. Based on the actual parameter of the biomass carbonisation reactor, a geometrical model was developed, and the computation of the heating process was conducted for two cases: an empty reactor and a filled reactor. Its result demonstrated that for the analysed configuration of the reactor, the process of heating biomass in the containers is limited by the capability of heat transfer to the biomass in the container. The results suggest opportunities for the improved heat exchange in the reactor and, accordingly, shortening heating time through installation of the system that forces circulation of hot air inside the reactor.
\end{abstract}

\section{Introduction}

Charcoal is used in many domains of life. Depending on the method of its production and physicochemical properties, charcoal can be used as a fuel, a component for production of absorbents (activated carbon), a component of fertilisers, and an additive to soil aimed to improve water retention [1]. Production of charcoal occurs in the reactors through thermal processing of biomass at temperatures from 300 to $700^{\circ} \mathrm{C}$ with no or minimal amount of oxygen. Regardless of the reactor design, charcoal production occurs at several stages, including biomass pre-heating, drying and heating, to reach temperature of initiation of autothermal process reaction, which is around $280-300^{\circ} \mathrm{C}$. In this part of thermal processing of biomass, it is unnecessary to supply heat from the outside to the process of biomass carbonisation, whereas it is needed to cover the reactor heat loss to its surroundings.

From the standpoint of the charcoal production, the biggest limitation in obtaining high efficiency is a stage connected with the process of providing heat to biomass in order to pre-heat it, dry and heat to the temperature of initiation of autothermal process of biomass carbonisation.

The study presents numerical analysis of the process of heat exchange in the biomass carbonisation reactor with cyclic operation.

\section{Biomass carbonisation reactor}

There is a number of types of biomass carbonisation reactors. They can be divided according to the operation: continuous or cyclic [2-5, 7]. The reactors that work continuously use mostly augers or other systems that allow for transport of biomass inside the retort (pipe), which is mostly heated with the heat generated from combustion of gases released during biomass carbonisation. After start-up, biomass is supplied to such reactors continuously, generating charcoal with specific physical and chemical parameters. In reactors with cyclic operation, the dose of the biomass is supplied to the reactor chamber, where processes of its drying and devolatilisation (carbonisation) occur. After set time when the biomass dose remains at required temperature in the reactor, it is carbonised and charcoal with specific parameters is obtained [6, 8-14].

The study presents the analysis of the process of heat exchange in the biomass carbonisation reactor with cyclic operation. The analysed carbonisation reactor (Fig. 1) was composed of gas combustion chamber (1) and two working chambers (2). Each chamber (2) was equipped in four containers (3) with carbonised biomass. The process of thermal processing of biomass was performed by heating the biomass in the containers (3) using a heating channel installed in the lower part of the reactor (4) in which the exhaust gas with maximal temperature of $750^{\circ} \mathrm{C}$ flowed from the combustion chamber (1) through a system of gate valves and channels $(5,6)$. The gases generated in the process of biomass carbonisation were transported to the combustion chamber (1) from containers (3) through the channel (7 and 8). By changing the position of gate valves (5 and 6), the flow of hot gases can be moved to the right or left reactor chamber.

Heating channels were located in the bottom part of the reactor (Fig. 2), with maximal operating temperature of $750^{\circ} \mathrm{C}$.

The containers filled with biomass were located inside the reactor (Fig. 3a). View of biomass carbonised in the container is presented in Fig. 3b.

The carbonisation process begins from introduction of four containers filled with biomass to the reactor chamber (4) and heating them by means of heating

*Corresponding author: zarzycki@is.pcz.czest.pl 
channels (Fig. 2) until completion of the release of gases from biomass. The experimental examinations of the biomass carbonisation process [16-18] showed that the heat exchange process in the biomass carbonisation reactor has a significant effect on efficiency and duration of the carbonisation process.

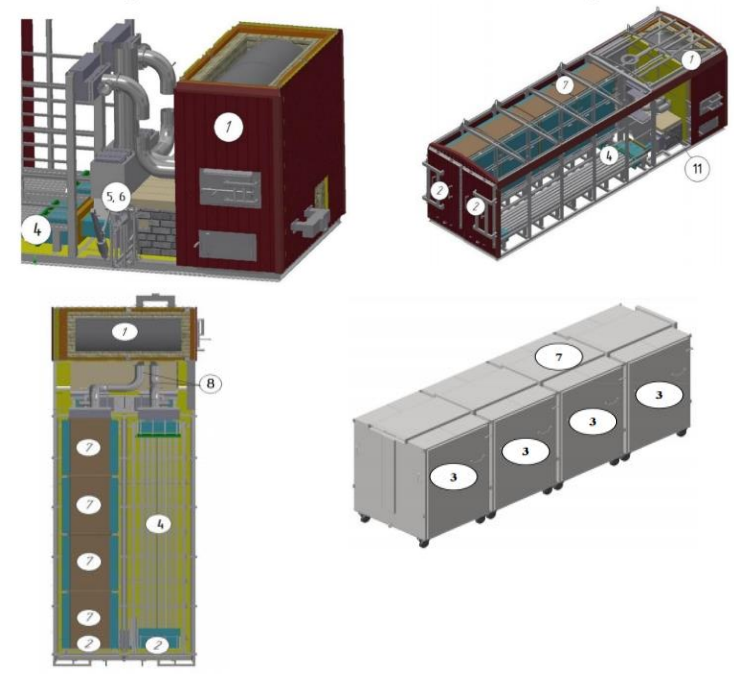

Fig. 1. Design of a reactor CK-4<<EURO >> [15].

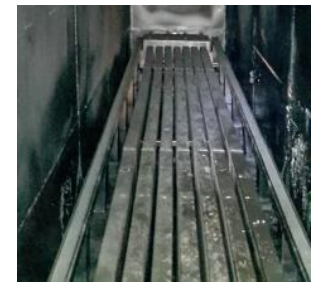

Fig. 2. Interior of biomass carbonisation reactor, view of heating channels.

a)

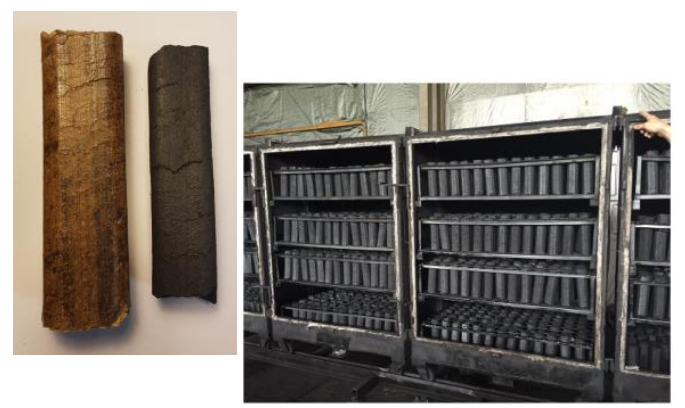

Fig. 3. Briquettes before and after carbonisation (a) and view of distribution of briquettes after carbonisation in the container (b) [15].

\section{Modelling of heat exchange process in the biomass carbonisation reactor}

The process of thermal processing of biomass (stored in the containers) is performed by indirect heating by means of heating channels placed in the lower part of the reactor with temperature of $750^{\circ} \mathrm{C}$.

Based on actual dimensions of the reactor chamber, channels and containers with biomass, the geometry was

prepared in the COMSOL software, allowing for the computations of the heat exchange process. The process of heat exchange in the reactor included conduction, radiation and convection. In the case of data on the literature data [19], parameters regarding thermal capacity and wood conductivity were adopted.

The diagram of the reactor cross-section is presented in Fig. 4. The reactor chamber is composed of seven heating channels, thermal insulation and the container used to store carbonised biomass. The distance between individual heating channels is $0.025 \mathrm{~m}$, whereas they are at the distance from the reactor chamber walls of $0.25 \mathrm{~m}$. They are placed at the height of $0.085 \mathrm{~m}$ from the reactor's bottom, whereas the distance from their upper surface to lower part of the container is $0.17 \mathrm{~m}$. Total internal dimensions of the reactor are: height of $1.85 \mathrm{~m}$ and width of $1 \mathrm{~m}$. Thickness of external insulation is $0.1 \mathrm{~m}$. Dimensions of the container introduced to the chamber are: width of $0.9 \mathrm{~m}$, height of $1.38 \mathrm{~m}$, length of $1.12 \mathrm{~m}$. Due to the substantial length of the container $(1.12 \mathrm{~m})$, the process of heating the reactor and reactor with charge can be simplified to the two-dimensional problem. The initial condition was adopted that the temperature of the reactor interior is $20^{\circ} \mathrm{C}$, whereas the temperature of heating channels is constant $\left(750^{\circ} \mathrm{C}\right)$. The air temperature around the reactor is $20^{\circ} \mathrm{C}$. The computations took into consideration the values of specific heat of structural components of the reactor and biomass, mass of individual components (reactor, container, biomass), values of heat transfer coefficients for structural components of the reactor and biomass briquettes.

The model of heat exchange also includes thermal conductivity processes in structural components of the reactor and in biomass briquettes and process of natural air convection inside the reactor and container. Due to the process of heating of interior of the reactor and the container, computations were performed with the time step of $0.1 \mathrm{~s}$ for the time $3600 \mathrm{~s}$ (empty container - C0) and $7200 \mathrm{~s}$ (container filled with biomass briquettes C1). View of geometry of the computation cross-section of the reactor and the computation grid are presented in Figs. 4 and 5, respectively.

a)

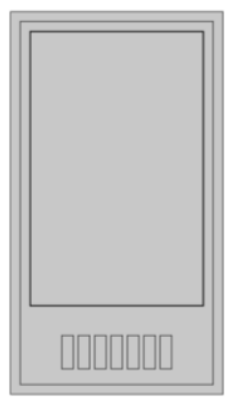

Fig. 4. Geometry of biomass carbonisation reactor $\mathbf{C O}$ (a), geometry of biomass carbonisation reactor with computation grid (b). 
a)

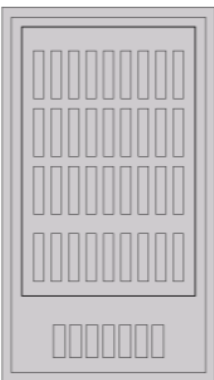

b)

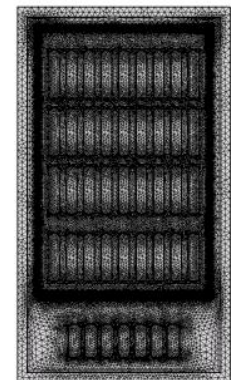

Fig. 5. Geometry of biomass carbonisation reactor filled with biomass briquettes $\mathbf{C 1}$ (a), geometry of biomass carbonisation reactor filed with biomass and computation grid (b).

\section{Analysis of heat exchange process in the biomass carbonisation reactor}

The results of computations of the heat exchange process for the case of empty reactor (C0) are presented in Figs. 6-8. Duration of the process of heating of the empty container was limited to $3600 \mathrm{~s}$. Analysis of instantaneous distributions of velocities and gas temperature reveals a strong effect of convection on gas and heat flow in the reactor space between its internal walls and container. With the difference in temperature (density), hot air circulates around the container placed in the chamber whereas heat flux is transferred through container walls due to gas circulation and heats air inside the container. It is observed in this case that the temperature in the reactor after $1500 \mathrm{~s}$ reaches $300^{\circ} \mathrm{C}$. At the initial phase of the heating process, the effect of convection that impacts on gas flow and intensifies heat exchange is noticeable while the temperature rises inside the container leads to lower intensity of convection and, consequently, a lower rate of heat transfer to its interior.

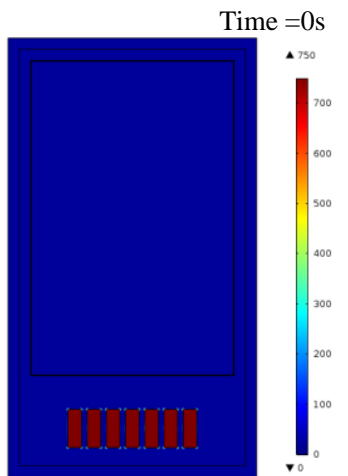

Time $=60 \mathrm{~s}$
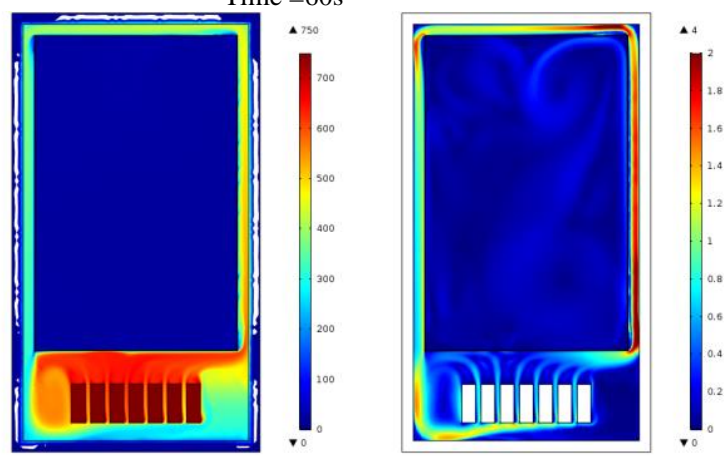

Fig. 6a. The temperature field $\left[{ }^{\circ} \mathrm{C}\right]$ (a) and gas velocity field $[\mathrm{m} / \mathrm{s}]$ (b) at specific time points for the case of $\mathbf{C 0}$.
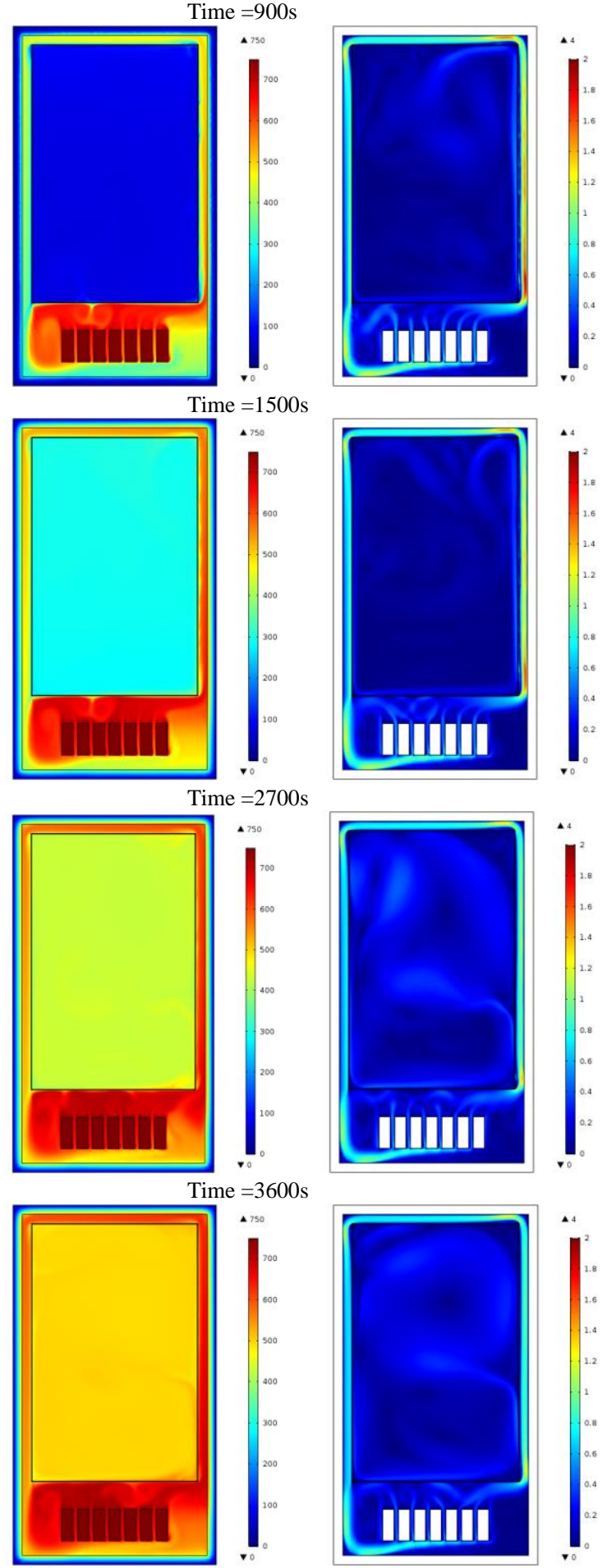

Fig. 6b. The temperature field $\left[{ }^{\circ} \mathrm{C}\right]$ (a) and gas velocity field $[\mathrm{m} / \mathrm{s}](\mathrm{b})$ at specific time points for the case of $\mathbf{C O}$.

The detailed insight into the heating process can be obtained by analysis of temperature distribution in the vertical and horizontal axes of the reactor at specific time points (Fig. 7 and 8). Analysis of Fig. 7 reveals an area of higher temperatures that increase with time over and below the container, resulting from the flow of hot gas forced by natural convection. Constant temperature can be observed in the container space, which gradually increases, reaching a mean value of $300^{\circ} \mathrm{C}$ after $1500 \mathrm{~s}$. Fig. 8 shows slightly higher temperature values at the 
right side of container interior, which results from convection and heat transfer to the container interior. The gas flowing on the left side has a temperature lower by $100^{\circ} \mathrm{C}$. In the horizontal cross-section inside the container, no temperature differences are observed at specific time points between the axis and area near container walls.

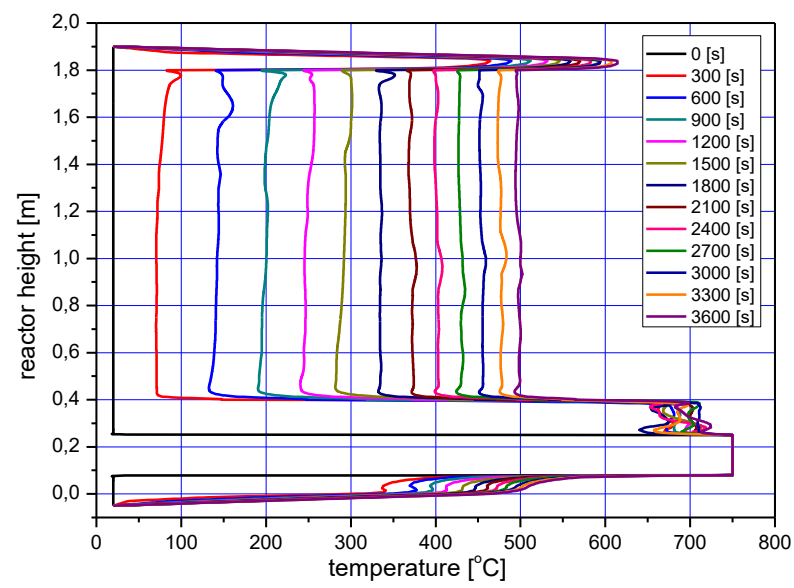

Fig. 7. Temperature distribution in vertical cross-section (axis) of the reactor chamber $\mathbf{C O}$.

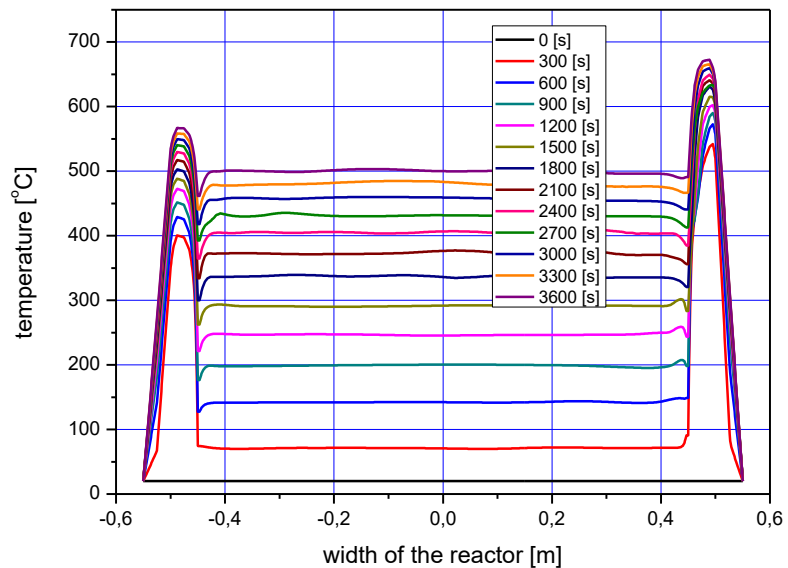

Fig. 8. Temperature distribution in horizontal cross-section (axis) of the reactor chamber $\mathbf{C 0}$.

Results of computations for the reactor filled with biomass briquettes (C1) are compared in Figs. 9-12. Briquettes with dimensions with height of $0.25 \mathrm{~m}$ and width of $0.05 \mathrm{~m}$ are placed at the distance of $0.04 \mathrm{~m}$ that fills the entire cross-section of the container (Fig. 5, 9.). The computations were started from the assumption that the reactor temperature and air temperature in the reactor is $20^{\circ} \mathrm{C}$, whereas briquette temperature is $10^{\circ} \mathrm{C}$. For simplification purposes it was adopted that briquettes do not contain humidity.

Results of the heating of the reactor filled with biomass briquettes at specific time points are compared in Fig. 9. The initial and boundary conditions of the process were identical as for the case of empty reactor, whereas simulation time was extended to $7200 \mathrm{~s}$. Analysis of the results presented in Figs. 9-12 reveals that the process of heating the volume of the reactor occurs in a similar manner, but greater amount of heat for heating the container interior (briquettes) is required due to the presence of biomass briquettes. Gas circulation is noticeable inside the container, resulting from the difference in temperature at the right and left side of the container (Fig. 9) (density difference). The hot air flowing around the side walls of the container leads to their heating and generation of the vertical gas flow inside the container near vertical walls. It is observed that hot air which reaches the container roof starts moving towards its axis, and "falls" on the "cold" briquettes and heats them. After $7200 \mathrm{~s}$, gas temperature in the upper part of the container reaches the level of $400-450^{\circ} \mathrm{C}$. It is noticeable that the process of briquette heating begins in the upper part of the container.

The condition for exothermal processes during biomass carbonisation is heating the biomass up to ca. $270-280^{\circ} \mathrm{C}$. Exceeding this level initiates a reaction that releases the heat during biomass carbonisation. For this reason, it is important to reach this temperature level during the carbonisation process and to compensate only for the heat loss to the surroundings in the further part of carbonisation.
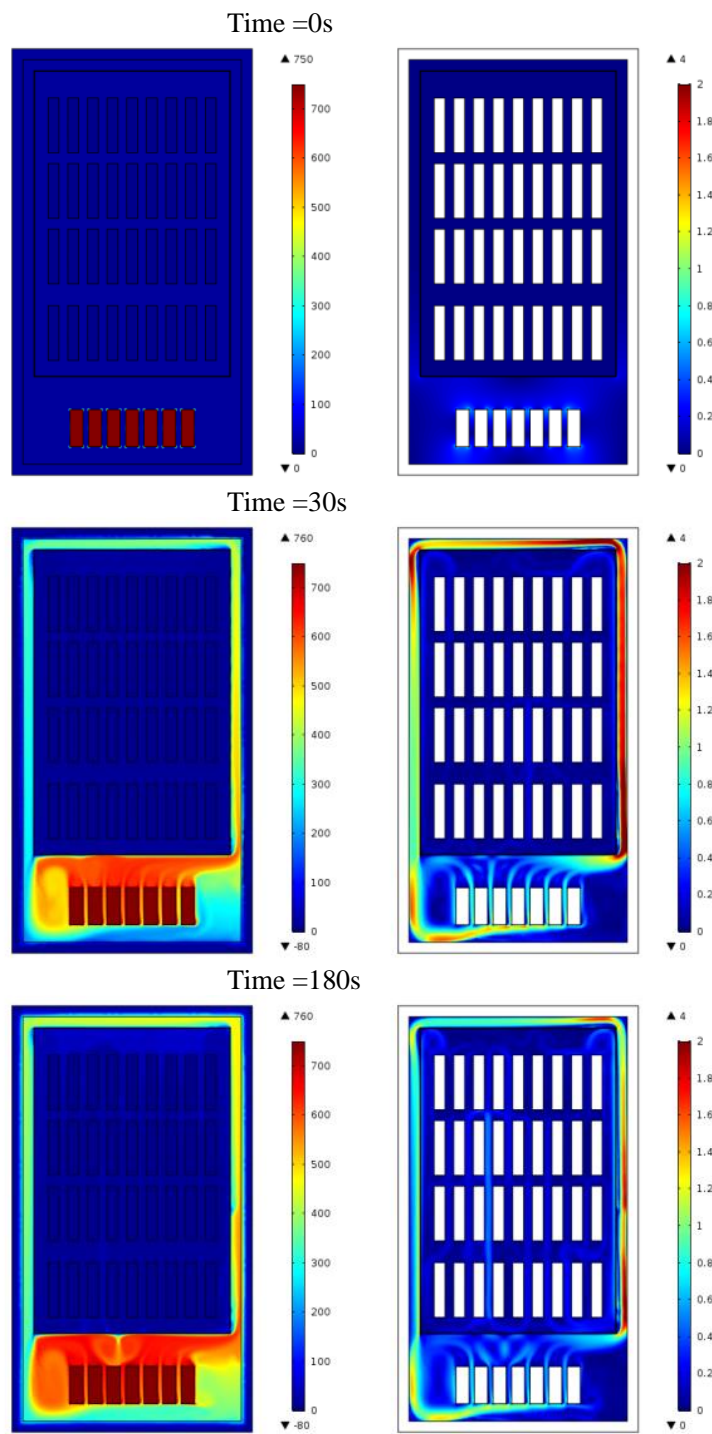

Fig. 9a. The temperature field $\left[{ }^{\circ} \mathrm{C}\right]$ (a) and gas velocity field $[\mathrm{m} / \mathrm{s}]$ (b) at specific time points for the case of $\mathbf{C 1}$. Time $=1200 \mathrm{~s}$ 

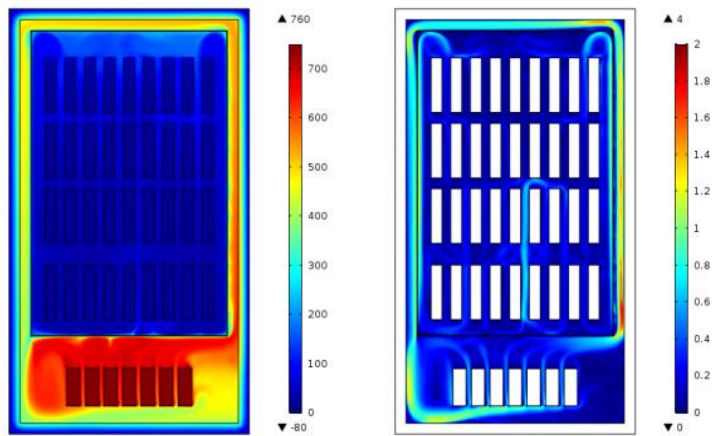

Time $=2700 \mathrm{~s}$
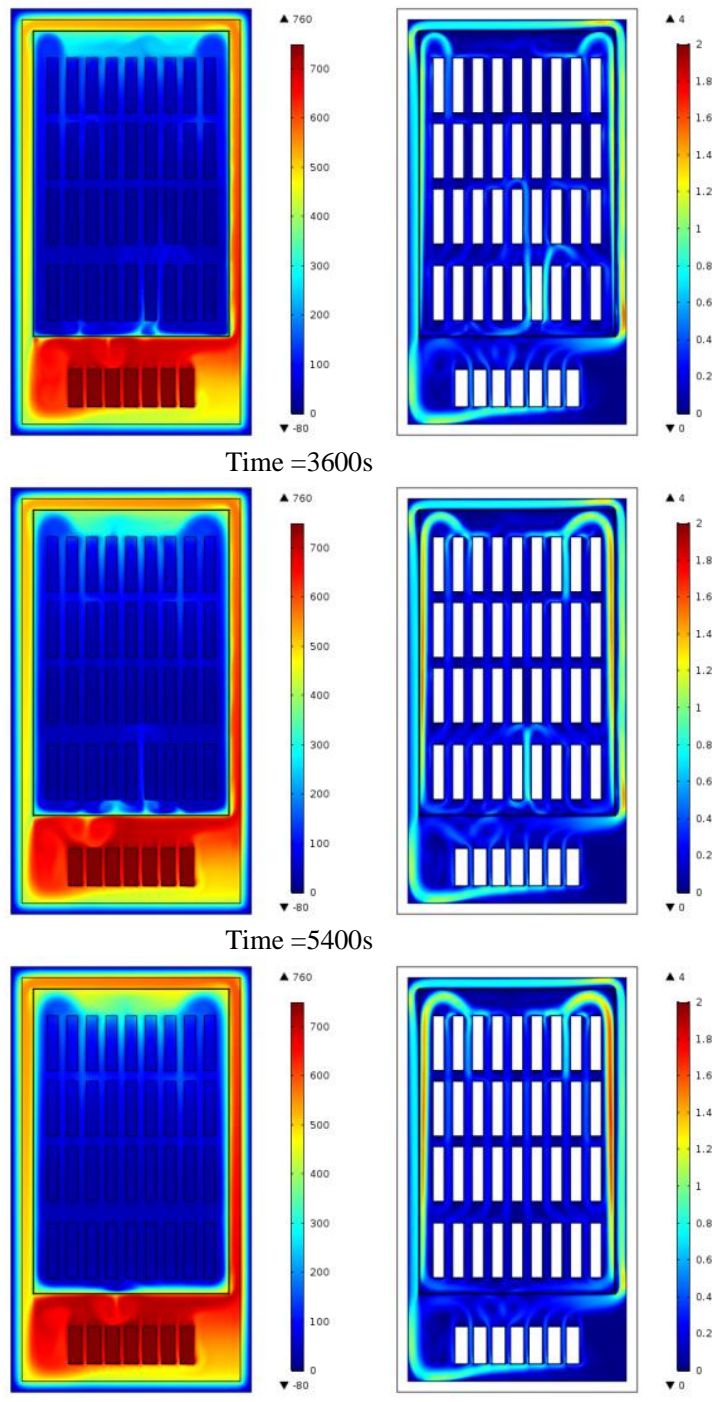

Time $=7200 \mathrm{~s}$
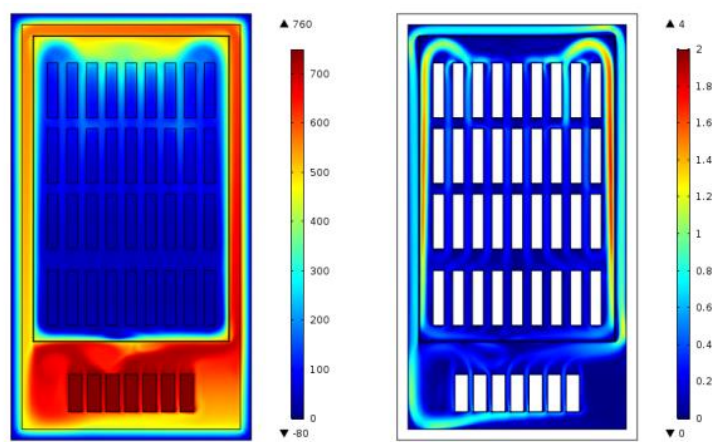

Fig. 9b. The temperature field $\left[{ }^{\circ} \mathrm{C}\right]$ (a) and gas velocity field $[\mathrm{m} / \mathrm{s}](b)$ at specific time points for the case of $\mathbf{C 1}$.
Detailed analysis of the process of briquette heating can be performed based on temperature profiles in the vertical and horizontal axes of the reactor at specific time points (Fig. 10 and 11). Similar to the case of empty reactor, the effect of the convection on temperature distribution inside the container can be observed. Presence of biomass briquette containers changes the rate of the increase of temperature of gas and briquettes (Fig. 10 and 11). As demonstrated above, the process of container interior heating begins from the container roof, which is noticeable in Fig. 11.

The detailed analysis of biomass briquette heating was observed in temperature profiles presented in Fig. 12. This figure presents the upper part of briquette (hatched areas in Fig. 12) and the gas filling the container present over this area. Analysis of the temperature fields shows a noticeable rise in temperature of gas contained in the upper part of the container and a substantially slower increase in temperature inside the briquette. After $7200 \mathrm{~s}$, the temperatures of $270-280^{\circ} \mathrm{C}$ (Fig. 12) were found in the upper part of briquettes. These temperatures were adopted as the beginning of exothermal reactions that occur during biomass carbonisation. Since this instant it is necessary to compensate for the heat loss to surroundings, whereas heat to heating further biomass doses will be transferred from the neighbouring carbonised biomass briquettes.

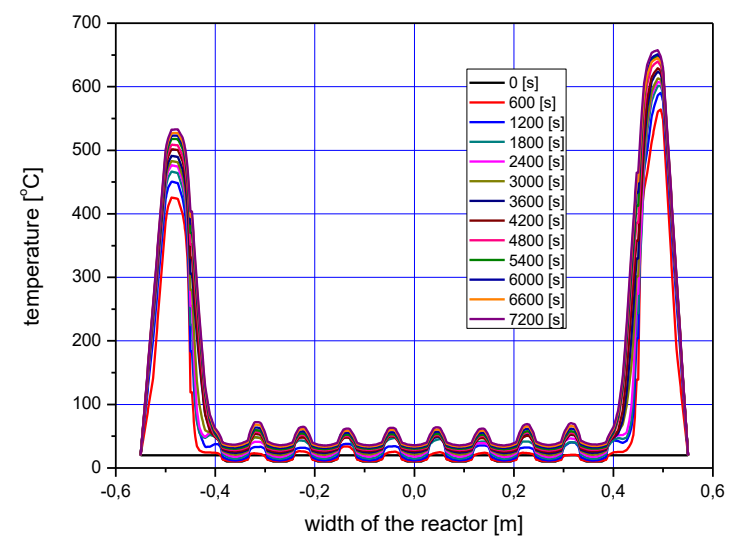

Fig. 10. Temperature distribution in the horizontal crosssection (axis) of the reactor chamber $\mathrm{C} 1$.

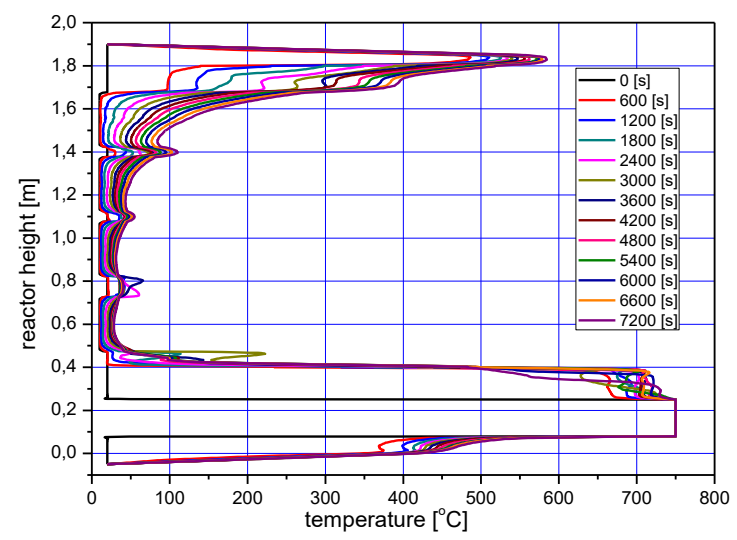

Fig. 11. Temperature distribution in the vertical cross-section (axis) of the reactor chamber $\mathbf{C 1}$. 


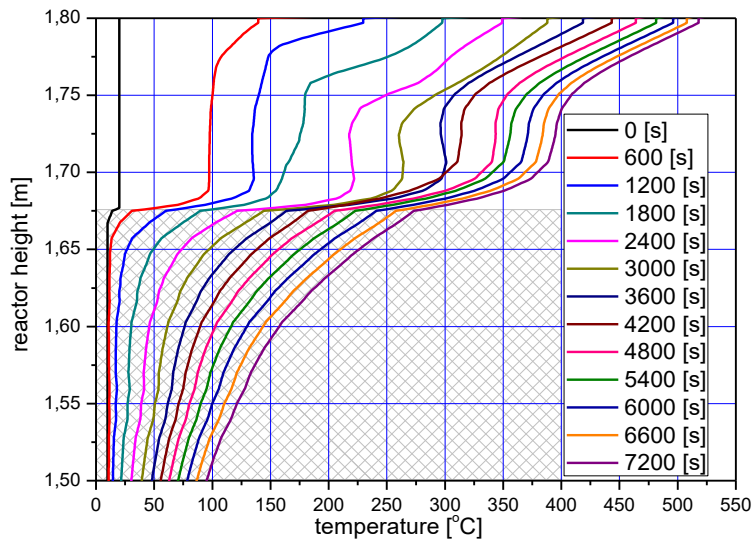

Fig. 12. Temperature distribution in the vertical cross-section (axis) of the reactor chamber near the highest level of biomass briquettes $\mathbf{C 1}$.

\section{Conclusion}

The results of computations of the heat exchange process presented in this study showed that the major barrier to the process of heat transfer from heating channels to the container interior is the process of heat transfer near the container wall. In the case of the empty container, the temperature of ca. $300^{\circ} \mathrm{C}$ was obtained after $1500 \mathrm{~s}$. For the reactor filled with biomass briquettes, the required time to reach the temperature of $300^{\circ} \mathrm{C}$ is ca. $7200 \mathrm{~s}$, resulting from greater thermal capacity of the reactor filled with biomass. The increased heat flux for the heat transferred to biomass can be obtained through intensification of heat exchange in the reactor through e.g. additional mechanical constraint of hot air flow (support for natural convection). However, this does not improve heat exchange inside the container filled with briquettes.

The increase in the efficiency of the analysed reactor can be also achieved by increasing the operating chamber and, therefore, the number of containers which are simultaneously carbonised. In this case, one should not expect shortening carbonisation time. However, it will be possible to achieve greater batches of charcoal in a single production cycle.

The results presented in the paper were obtained in a project co-financed by NCBR within the contract No. BIOSTRATEGG3/345940/7/ NCBR/2017 titled Water in soil: satellite monitoring to improve water retention using biochar (project acronym: SoilAqChar).

\section{References}

1. K. Qian, A. Kumar, H. Zhang, D. Bellmer, R. Huhnke, Renew Sust Energ Rev. 42 (2015)

2. M.J. Antal, K. Mochidzuki, L. S. Paredes, Ind. Eng. Chem. Res. 42 (16) (2003)

3. D.C. Elliot, Biomass, chemicals from (Encyclopedia of Energy, Elsevier Academic Press, Amsterdam, 2004)

4. S. Szernick, A.V., Energy Fuels 18 (2004)

5. M.J. Antal, M. Grønli, Ind. Eng. Chem. Res. 42 (2003)

6. P. McKendry, Bioresour Technol. 83 (2002)

7. W.S.-L. Mok, M.J. Antal Jr., P. Szabo, G. Varhegyi, B. Zelei, Ind Eng Chem Res. 31 (1992)

8. L. Zhang, C. Xu, P. Champagne, Energy Convers Manag. 51, 5 (2010)

9. A. Demirbas, G. Arın, Energy Source, Part A 24 (2002)

10. I. Agirre, T. Griessacher, G. Rösler, J. Antrekowitsch, Fuel Process. Technol. 106 (2013)

11. J. Solar, I. de Marco, B.M. Caballero, A. LopezUrionabarrenechea, N. Rodriguez, I. Agirre, A. Adrados, Biomass Bioenergy 95 (2016)

12. S. Rapagna, E. Tempesti, P.U. Foscolo, E. Parodi, J Therm Anal. 38 (1992)

13. A.V. Bridgewater, D. Meier, D. Radlein, Org Geoche. 30 (1999)

14. R. Bailis, C. Rujanavech, P. Dwivedi, A. de Oliveira Vilela, H. Chang, R. Carneiro de Mirandac, Energy Sustain Dev. 17, 2, (2013)

15. http://greenpower.com.ua/

16. M. Kratofil, R. Zarzycki, R. Kobyłecki, Z. Bis, Polityka Energetyczna 17, 4 (2014)

17. M. Kratofil, R. Zarzycki, R. Kobyłecki, Z. Bis, Mechanika 87(2/15) (2015)

18. R. Kobyłecki, Środowiskowe aspekty termolizy biomasy, Monografia 290, (Wydawnictwo Politechniki Częstochowskiej, Częstochowa 2014)

19. www.engineeringtoolbox.com 